CARDIOVASCULAR MEDICINE

\title{
Giant cell arteritis and cardiovascular disease in older adults
}

\author{
J G Ray, M M Mamdani, W H Geerts
}

Heart 2005;91:324-328. doi: 10.1136/hrt.2004.037481

See end of article for authors' affiliations ....................

Correspondence to: Dr Joel G Ray, Department of Medicine, Inner City Health, St Michael's

Hospital, 30 Bond Street, Toronto, Ontario, Canada M5B 1W8; JRay515445@ aol.com

Accepted 10 May 2004

\begin{abstract}
Objective: To explore the association between giant cell arteritis (GCA) and subsequent cardiovascular disease in older adults.

Design: Population based retrospective cohort study.

Setting: The entire province of Ontario, Canada.

Participants: Patients aged 66 years and older with newly diagnosed GCA $(n=1141)$, osteoarthritis $(n=172953)$, or neither $(n=200000)$. Patients with neither were randomly selected from the general population and formed the control group.

Main outcome measures: The primary composite outcome was based on a subsequent diagnosis or surgical treatment for coronary artery disease, stroke, peripheral arterial disease, or aneurysm or dissection of the aorta.

Results: The composite end point was more common in seniors with GCA (12.1/1000 person-years) than in patients with osteoarthritis (7.3/1000 person-years) or neither condition (5.3/1000 person-years). The adjusted hazard ratio for cardiovascular disease was 1.6 (95\% confidence interval (CI) 1.1 to 2.2 ) in patients with GCA versus patients with osteoarthritis, and 2.1 (95\% Cl 1.5 to 3.0) in patients with GCA versus unaffected controls.

Conclusions : Older adults with GCA appear to be at increased risk for developing cardiovascular disease. Whether an aggressive approach to cardiovascular risk factor modification is particularly beneficial in these patients remains to be determined.
\end{abstract}

\section{G} iant cell arteritis (GCA), a granulomatous vasculitis of the older adult, often manifests as temporal arteritis, sometimes in association with polymyalgia rheumatica. ${ }^{1}$ With potential involvement of the aorta and its branches, the complications of GCA also include myocardial infarction, ${ }^{2}$ stroke, ${ }^{3}$ aneurysm or dissection of the aorta, ${ }^{4}$ and lower limb arterial thrombosis. ${ }^{5}$ Associations have also been found between GCA and Chlamydia pneumoniae infection, ${ }^{6}$ cardiolipin antibodies, ${ }^{7}$ and chronic inflammation, ${ }^{8}$ each of which is a suspected risk factor for myocardial infarction, stroke, and aortic disease. ${ }^{9-15}$

Knowledge about the extent to which a chronic disorder, such as GCA, alters the risk of cardiovascular disease not only may influence how affected patients are cared for but also may enhance our understanding of the role of chronic inflammation in the pathogenesis of arterial disease. ${ }^{15}$ Previous studies were underpowered to detect either a statistically or clinically significant association between GCA and subsequent vascular events. ${ }^{4{ }^{16}}$ Moreover, the absence of a properly selected control group has limited the interpretability of these study results. Therefore, we evaluated the risk of subsequent cardiovascular disease in a large group of senior adults with GCA and compared it with the risk in patients with osteoarthritis and with unaffected population controls.

\section{PATIENTS AND METHODS}

We retrospectively studied a cohort over a 10 year period through use of linked provincial health care administrative databases of 1.5 million senior residents of Ontario, Canada. Under the Ontario Health Insurance Plan (OHIP), universal health care is provided free to every person after the age of 65 years. Similarly, the cost of prescribed medications to all seniors is covered under the Ontario Drug Benefits program, with the exception of a small annual fee.
We identified three mutually exclusive study cohorts: patients with GCA; patients with osteoarthritis; and patients with neither condition, the passive reference group. We selected patients with osteoarthritis as the active referent because they may exhibit additional risk factors for cardiovascular disease, ${ }^{18}$ a decision recently used by others. ${ }^{19}$ The GCA and osteoarthritis study groups comprised people aged 66 years and older with newly diagnosed GCA or osteoarthritis between 1 January 1995 and 31 March 2002. The unaffected control group consisted of 200000 randomly selected patients older than 65 years of age with no diagnosis of GCA or osteoarthritis during the period of study. This cohort was created by assigning each resident of Ontario a randomly selected index date between 1 January 1995 and 31 March 2002 by a random number generator in SAS for UNIX version 8.2 (SAS Institute, Cary, North Carolina, USA). Patients aged 66 years and older who were alive on the assigned index date were screened for a diagnosis of GCA or osteoarthritis. From among those without a diagnosis of either disease within 36 months before or throughout the observation period, we randomly selected 200000 patients by a random number generator to form the passive control cohort.

In the 36 month period before study entry, we excluded patients from all three groups if they had a diagnosis of GCA, polymyalgia rheumatica, osteoarthritis, coronary artery disease, stroke, peripheral arterial disease, abdominal or thoracic artery aneurysm or dissection, or cancer. Because of its potent antithrombotic effect, warfarin prescribed within 12 months before study entry also was an exclusion criterion. We

Abbreviations: GCA, giant cell arteritis; HR, hazard ratio; ICD-9, International classification of diseases, 9th revision; OHIP, Ontario Health Insurance Plan 
adjusted for newly prescribed warfarin or newly diagnosed cancer if either occurred after study entry, as outlined below.

The primary cardiovascular disease outcome was a composite diagnosis or surgical treatment of any one of the following: coronary artery disease, stroke, peripheral arterial disease, or aneurysm or dissection of the aorta. Coronary artery disease was defined according to the International classification of diseases, 9th revision, (ICD-9) codes related to angina, myocardial infarction, or coronary artery revascularisation (see Appendix). Cerebrovascular disease was defined by all ICD-9 codes related to stroke or carotid endarterectomy. Peripheral arterial disease was based on a coding for peripheral vascular disease or peripheral artery revascularisation. Aneurysm or dissection the aorta required a coded diagnosis of either condition in the non-ruptured, ruptured, or surgically repaired state (see Appendix). It was a requisite that a diagnosis of GCA or osteoarthritis precede the diagnosis of cardiovascular disease.

The period of observation was from 1 January 1995 to 31 March 2002. The databases were sampled from 1 January 1992 to 31 March 2002 to account for the presence of antecedent inclusion and exclusion criteria. A participant in one exposure group was censored either if he or she had a disease diagnosis from another group or if he or she experienced a cardiovascular disease outcome event, died during the study period, or reached the end of follow up to 31 March 2002.

Hospitalisation records were obtained from the Canadian Institute for Heath Information Discharge abstract database, which was used to categorise patients as having GCA, osteoarthritis, or neither, as well as all subsequent events and co-morbid illnesses, both diagnostic and procedural. Discharge abstract database records contain the unique health care number, age and sex of the patient, date of admission, and up to 16 diagnoses coded according to the ICD-9 system (see Appendix). The OHIP database was also used to identify baseline and subsequent disease events. This database contains records of all physician billing information for outpatient and inpatient services, including a service date and diagnosis. Participant age and sex were retrieved from the Registered persons database, which contains demographic information and health care numbers for all people eligible for OHIP. Finally, the Ontario drug benefits database was used to identify the medications each elderly participant was prescribed at any point during the period of observation, irrespective of the number of prescriptions or days supplied. This database is maintained by the Ontario Ministry of
Health and Long-Term Care and records encrypted patient identifiers, prescription dates, and drug information for all residents of Ontario aged 65 years or greater.

\section{Statistical analysis}

Time to event was analysed by Cox's proportional hazards regression model. Risk was expressed as an unadjusted and adjusted hazard ratio (HR) and 95\% confidence interval (CI). Age, sex, hospitalisation within one year before study entry, newly diagnosed cancer, currently prescribed medications for the treatment of hyperglycaemia or hypertension, and current prescription of a lipid lowering agent, aspirin, warfarin, oestrogen, non-steroidal anti-inflammatory drug (including cyclo-oxygenase 2 (COX-2) inhibitors), or prednisone, methylprednisone, azathioprine or methotrexate were the adjusted factors. All participants were identified as being exposed to a potential confounder if the confounding event occurred at any time between 100 days before study entry and the end of follow up.

All $p$ values were two sided at a significance level of 0.05 . All statistical analyses were performed with SAS for UNIX version 8.2. The three health care databases were linked anonymously by encrypted individual health card numbers. The control group of 200000 unaffected patients were selected to ensure that at least $10 \%$ of the existing population of seniors would form that group. This study was approved by the ethics review board of Sunnybrook and Women's College Health Sciences Centre, Toronto.

\section{RESULTS}

A total of 1141 patients with GCA, 172953 patients with osteoarthritis, and 200000 unaffected controls were studied, corresponding to 3061, 434 025, and 640637 person-years of follow up (table 1). Of the patients with a diagnosis of GCA, $283(25 \%)$ had a submitted physician OHIP billing code for temporal artery biopsy within 30 days of the index date of diagnosis. The general characteristics and respective drug prescription rates were similar among patients with GCA, osteoarthritis, and neither, with the exception of prescribed antihyperglycaemic drugs $(16 \%, 12 \%$, and $11 \%)$, lipid lowering drugs $(25 \%, 24 \%$, and $21 \%)$, aspirin $(28 \%, 22 \%$, and $21 \%)$, non-steroidal anti-inflammatory drugs $(34 \%, 49 \%$, and $37 \%)$, and systemic corticosteroids $(47 \%, 12 \%$, and $14 \%$, respectively) (table 1).

For the primary composite outcome, there were 37 (12.1/ 1000 person-years) cardiovascular events in the GCA group, 3172 (7.3/1000 person-years) events in the osteoarthritis

Table 1 Baseline characteristics of the study cohort

\begin{tabular}{llll}
\hline & \multicolumn{3}{l}{ Disease exposure group } \\
\cline { 2 - 4 } Measurement & $\begin{array}{l}\text { GCA } \\
(\mathbf{n}=1141)\end{array}$ & $\begin{array}{l}\text { Osteoarthritis } \\
(\mathbf{n}=172953)\end{array}$ & $\begin{array}{l}\text { Unaffected controls } \\
(\mathbf{n}=200000)\end{array}$ \\
\hline Duration of follow up (person-years) & 3061 & 434025 & 640637 \\
Age (years) & $75.2(6.5)$ & $74.9(6.8)$ & $74.7(7.0)$ \\
Men & $463(41 \%)$ & $67429(39 \%)$ & $82574(41 \%)$ \\
Cancer & $33(3 \%)$ & $3180(2 \%)$ & $3474(2 \%)$ \\
Medication & $187(16 \%)$ & $21046(12 \%)$ & $22313(11 \%)$ \\
Antihyperglycaemic drug & $98(9 \%)$ & $15353(9 \%)$ & $15120(8 \%)$ \\
Oestrogen & $288(25 \%)$ & $41764(24 \%)$ & $41948(21 \%)$ \\
Lipid lowering drug & $322(28 \%)$ & $38318(22 \%)$ & $41639(21 \%)$ \\
Aspirin & $76(7 \%)$ & $7118(4 \%)$ & $10197(5 \%)$ \\
Warfarin & $386(34 \%)$ & $84872(49 \%)$ & $74226(37 \%)$ \\
NSAID & $540(47 \%)$ & $20163(12 \%)$ & $27016(14 \%)$ \\
Prednisone or methylprednisone & $12(1 \%)$ & $125(<1 \%)$ & $1416(<1 \%)$ \\
Methotrexate & $4(<1 \%)$ & $254(<1 \%)$ & $1768(<1 \%)$ \\
Azathioprine & \multicolumn{3}{l}{} \\
\hline Data are mean (SD) or number (\%). & \multicolumn{3}{l}{} \\
GCA, giant cell arteritis; NSAID, non-steroidal anti-inflammatory drug. & \\
\hline
\end{tabular}


Table 2 Major cardiovascular events (rate per 1000 person-years) among seniors with GCA relative to patients with osteoarthritis or to unaffected controls

\begin{tabular}{|c|c|c|c|c|c|c|c|}
\hline \multirow[b]{2}{*}{ Event } & \multirow{2}{*}{$\begin{array}{l}\begin{array}{l}\text { GCA } \\
(\mathrm{n}=1141)\end{array} \\
\text { Number (rat }\end{array}$} & \multirow[t]{2}{*}{$\begin{array}{l}\text { Osteoarthritis } \\
\text { ( } n=172953 \text { ) }\end{array}$} & \multirow[t]{2}{*}{$\begin{array}{l}\text { Unaffected controls } \\
(\mathrm{n}=200000)\end{array}$} & \multicolumn{2}{|c|}{ GCA $v$ unaffected controls } & \multicolumn{2}{|c|}{ GCA $v$ osteoarthritis } \\
\hline & & & & $\begin{array}{c}\text { Crude HR } \\
(95 \% \mathrm{Cl})\end{array}$ & $\begin{array}{l}\text { Adjusted HRT } \\
(95 \% \mathrm{CI})\end{array}$ & $\begin{array}{l}\text { Crude HR } \\
(95 \% \mathrm{Cl})\end{array}$ & $\begin{array}{l}\text { Adjusted HRT } \\
(95 \% \mathrm{CI})\end{array}$ \\
\hline CVD composite* & $37(12.1)$ & $3172(7.3)$ & $3401(5.3)$ & 2.4 (1.7 to 3.3$)$ & 2.1 (1.5 to 3.0 ) & $1.6(1.2$ to 2.2$)$ & $1.6(1.1$ to 2.2$)$ \\
\hline CAD & $25(8.2)$ & $2350(5.4)$ & $2567(4.0)$ & 2.1 (1.4 to 3.2$)$ & $1.9(1.2$ to 2.7$)$ & 1.5 (1.0 to 2.2$)$ & $1.4(0.9$ to 2.1$)$ \\
\hline Stroke & $6(1.9)$ & $551(1.3)$ & $600(0.9)$ & $2.2(1.0$ to 4.9$)$ & $2.1(0.9$ to 4.6$)$ & $1.5(0.7$ to 3.4$)$ & $1.5(0.7$ to 3.5$)$ \\
\hline PAD & $3(1.0)$ & $128(0.3)$ & $125(0.2)$ & $5.2(1.7$ to 16.5$)$ & 4.7 (1.5 to 14.9$)$ & $3.2(1.0$ to 10.2$)$ & $2.8(0.9$ to 8.8$)$ \\
\hline $\begin{array}{l}\text { Aortic aneurysm } \\
\text { or dissection }\end{array}$ & $3(1.0)$ & $176(0.4)$ & $187(0.3)$ & $3.5(1.1$ to 11.0$)$ & $3.2(1.0$ to 10.1$)$ & $2.4(0.8$ to 7.4$)$ & $2.3(0.7$ to 7.3$)$ \\
\hline $\begin{array}{l}\text { *Diagnosis of cor } \\
\text { †Adjusted for age } \\
\text { hyperglycaemia o } \\
\text { inhibitors), or pre } \\
\mathrm{Cl} \text {, confidence int }\end{array}$ & $\begin{array}{l}\text { one, methy } \\
\text { l; CVD, ca }\end{array}$ & $\begin{array}{l}\text { dnisone, azat } \\
\text { vascular disea }\end{array}$ & $\begin{array}{l}\text { ripheral arterial disea } \\
\text { eefore study entry, ne } \\
\text { n of either a lipid low } \\
\text { ne, or methotrexate. } \\
\text {, hazard ratio. }\end{array}$ & ng agent, aspirin & warfarin, oestro & $\begin{array}{l}\text { f any medication } \\
\text { NSAID (includin }\end{array}$ & $\begin{array}{l}\text { r the treatment of } \\
\text { yclo-oxygenase } 2\end{array}$ \\
\hline
\end{tabular}

group, and 3401 (5.3/1000 person-years) events among the unaffected controls (table 2, fig 1). There was a heightened associated risk for cardiovascular disease among patients with diagnosed GCA compared with patients with osteoarthritis (crude HR 1.6, 95\% CI 1.2 to 2.2 ) or neither disease (crude HR 2.4, 95\% CI 1.7 to 3.3). After adjustment for certain potential confounders, the HR remained significant when patients with GCA were compared with the osteoarthritic (1.6, 95\% CI 1.1 to 2.2$)$ or unaffected $(2.1,95 \%$ CI 1.5 to 3.0) controls (table 2). This risk difference became more apparent with time (fig 1).

Compared with unaffected controls, there was a significant association between GCA and the crude risk of coronary artery disease (HR 2.1, 95\% CI 1.4 to 3.2), stroke (HR 2.2, 95\% CI 1.0 to 4.9 ), peripheral arterial disease (HR 5.2, 95\% CI 1.7 to 16.5), and aortic aneurysm or dissection (HR 3.5, 95\% CI 1.1 to 11.0) (table 2). After adjustment for potential confounders, all patient outcomes remained significant, with the exception of a non-significant trend for stroke (adjusted HR 2.1, 95\% CI 0.9 to 4.6 ) (table 2).

In a post hoc analysis, we limited the GCA cohort to patients who were prescribed corticosteroids. The incidence of the composite cardiovascular end point was higher among these 540 patients $(9.4 / 1000$ person-years $)$ than among patients with a diagnosis of osteoarthritis (7.3/1000 personyears) or neither condition (5.3/1000 person-years). In a comparison between patients with GCA prescribed steroids and unaffected controls, the crude HR was 1.9 (95\% CI 1.1 to 3.3). A non-significant trend remained after adjustment for all covariates except prescribed corticosteroids (adjusted HR $1.6,95 \%$ CI 0.9 to 2.8 ).

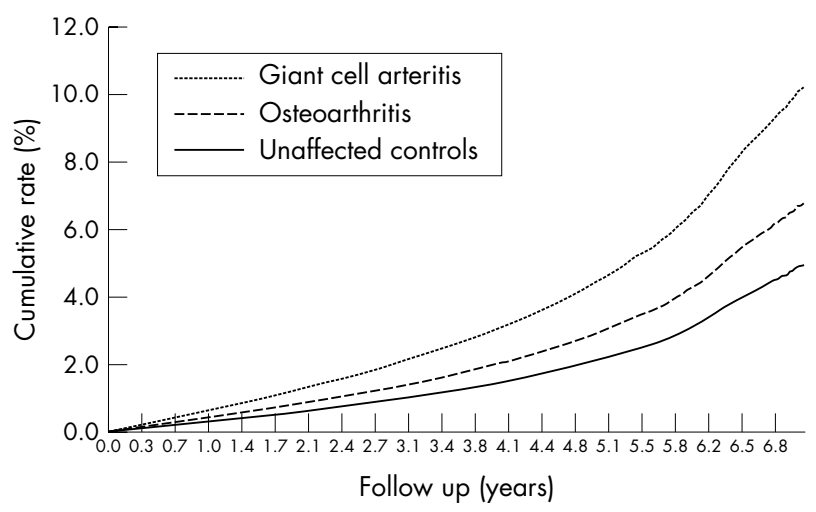

Figure 1 Cumulative rate of diagnosed cardiovascular disease among senior adults with giant cell arteritis, osteoarthritis, or neither.

\section{DISCUSSION}

In a large retrospective population based cohort study, we observed roughly a doubling of the associated risk of diagnosed cardiovascular disease among patients with GCA compared with unaffected controls and a $60 \%$ increased risk with GCA relative to patients with osteoarthritis.

\section{Study limitations}

The diagnosis of GCA depends on clinical symptoms and signs and is enhanced by non-specific (for example, erythrocyte sedimentation rate) and specific (for example, arterial biopsy) laboratory findings..$^{20}$ Only $25 \%$ of patients with a diagnosis of GCA had a procedural billing code submitted by a physician for temporal artery biopsy within 30 days of the diagnosis of GCA. This may be explained partly by delayed billing practices, the low reliability of procedural codes, and the fact that many cases of GCA are not biopsy proven.$^{20}$ However, since some patients with a diagnosis of GCA may not have had biopsy proven disease, disease exposure misclassification was a possibility-a limitation of using large administrative databases for research purposes. ${ }^{21}$ Non-differential misclassification (that is, an equal chance of misclassification of the exposure between diseased and nondiseased participants) would likely have led to an underestimate of the true relation between GCA and cardiovascular disease. $^{22}$ Although the diagnostic coding for cardiovascular disease $^{23}$ and related co-morbidity events ${ }^{24}$ appears to be accurate, it is possible that vascular disease was more commonly suspected or diagnosed in patients with GCA, partly because they may receive more thorough clinical care and follow up. Finally, although 1141 patients with GCA were studied, only six had a diagnosis of stroke and three of peripheral arterial disease or aortic disease, probably generating underpowered risk estimates. We were unable to identify whether these events were caused by atherothrombosis or aortitis.

\section{Other published evidence}

A higher associated risk between GCA or polymyalgia rheumatica and all cause mortality has been observed in previous small studies ${ }^{25}{ }^{26}$ but not consistently so. ${ }^{27}{ }^{28}$ Even less is known about the relation between GCA and cardiovascular disease. In one report of 96 patients with GCA, the incidence of thoracic and abdominal aortic aneurysm was higher than expected, at 1.0 and $0.6 / 1000$ person-years, respectively. ${ }^{4}$ In a second study, 171 patients with GCA or polymyalgia rheumatica were followed up for up to two decades. ${ }^{29}$ An increased risk of cardiovascular death was observed among both women (standardised mortality ratio $1.5,95 \%$ CI 1.2 to 1.9 ) and men (standardised mortality 
ratio $1.6,95 \%$ CI 1.1 to 2.2 ), mainly due to ischaemic heart disease. ${ }^{29}$

\section{Mechanisms of disease}

There are several plausible mechanisms to explain the observed association between GCA and cardiovascular disease. The focal vasculitis of GCA may produce acute arterial occlusion and secondary stroke or myocardial infarction or it can progress to luminal ectasia, with dissection or aneurysm of the aorta. ${ }^{30}$ GCA may also induce reactive thrombocytosis ${ }^{31}$ and hyperfibrinoginaemia, ${ }^{32}$ predisposing to atherothrombosis. $^{33}$ At a third level of reasoning, GCA and cardiovascular disease may share certain risk factors, such as heavy cigarette smoking. ${ }^{34}$ Similarly, $C$ pneumoniae infection ${ }^{6-11}$ and high cardiolipin antibody titres ${ }^{72} 13$ are each risk factors for both GCA and cardiovascular disease. In one study, C pneumoniae was isolated in eight of nine temporal artery biopsies of patients with GCA, predominantly from within the granulomatous infiltrates of the vascular adventitia, compared with none of the nine controls whose biopsies were negative for GCA. ${ }^{6}$ In a prospective case-control study, cardiolipin antibodies were present in $21 \%$ of all patients with GCA but in only $3 \%$ of controls. ${ }^{7}$ The prevalence of antibodies among patients whose temporal artery biopsy was GCA positive $(31 \%)$ was nearly twice that of patients with suspected cases whose biopsy was negative $(17 \%){ }^{7}$

Perhaps the most compelling contemporary explanation linking GCA with cardiovascular disease is the presence of chronic inflammation. A robust body of evidence supports a strong dose-response relation between markers of chronic inflammation and cardiovascular disease risk. ${ }^{14}{ }^{15}$ Inflammatory cytokines, including interleukin 6, are directly liberated from GCA granulomata. ${ }^{35}$ These cytokines potently stimulate production of fibrinogen and certain acute phase reactants, including $\mathrm{C}$ reactive protein, a strong risk marker for cardiovascular disease. ${ }^{15}$ Patients with inflammatory rheumatoid arthritis also appear to be at increased risk of cardiovascular disease. ${ }^{19}$ For example, a recent large comparative study of adults with rheumatoid arthritis and osteoarthritis found that patients with rheumatoid arthritis were at increased risk of myocardial infarction (adjusted risk ratio 1.3), stroke (adjusted risk ratio 1.3), and cardiovascular death (adjusted risk ratio 1.4). ${ }^{19}$ This association may be independent of the presence of underlying vasculitis ${ }^{36}$ and related more to increased serum $\mathrm{C}$ reactive protein and markers of the metabolic syndrome. ${ }^{37}$

The risk of the cardiovascular disease composite was significantly higher among patients with GCA than among patients with osteoarthritis but not for the individual subtypes of cardiovascular disease (table 2). This phenomenon may be explained both by a diminution in statistical power created by subgroup multivariate analysis and by the greater presence of cardiovascular risk factors among patients with osteoarthritis than among a non-arthritic population. ${ }^{18} 19$ For example, in the US third national health and nutrition examination survey of patients with osteoarthritis, the prevalence of hypertension was $40 \%$, hypercholesterolaemia $32 \%$, and diabetes mellitus $11 \%$, all of which are more commonly seen in overweight adults. ${ }^{18}$

Because of the low coding accuracy within administrative databases, ${ }^{38}$ we did not establish a control group of seniors with rheumatoid arthritis. Comparing patients with GCA versus patients with rheumatoid arthritis and estimating their relative risk of cardiovascular disease may clarify the degree to which chronic systemic inflammation is a mediator of vascular injury or arteriosclerosis. We saw only a minor decline in the estimated risk of cardiovascular disease among patients with GCA after adjusting for prescribed corticosteroids, azathioprine, or methotrexate in the multivariate model. At the same time, we could not precisely exclude some modifying effect of these agents, since cumulative drug doses were not documented.

\section{Clinical ramifications}

How do these data affect clinical management of GCA after the recommended use of immunosuppressive agents in the acute phase of the disease ? $^{17}$ Since preliminary data suggest that patients with GCA may be at increased risk of cardiovascular disease, they may particularly benefit from risk factor modification, including control of hypertension, hyperglycaemia, dyslipidaemia, and tobacco use. Low dose aspirin may attenuate the inflammatory response seen with

\section{APPENDIX}

\begin{tabular}{|c|c|c|}
\hline Disease & Diagnosis or procedure & ICD-9 code \\
\hline Giant cell arteritis & $\begin{array}{l}\text { Giant cell arteritis } \\
\text { Polymyalgia rheumatica* }\end{array}$ & $\begin{array}{l}446.5 \\
725\end{array}$ \\
\hline \multirow{4}{*}{$\begin{array}{l}\text { Osteoarthritis } \\
\text { Coronary artery } \\
\text { disease }\end{array}$} & Osteoarthritis & 715 \\
\hline & Angina & $413,414.0$ \\
\hline & $\begin{array}{l}\text { Myocardial infarction } \\
\text { Coronary angioplasty or coronary stent insertion or }\end{array}$ & 410,411 \\
\hline & coronary artery bypass grafting & $36.0,36.1,36.2,36.3$ \\
\hline \multirow[t]{2}{*}{ Stroke } & Stroke & $433,434,437.0,437.1$ \\
\hline & Cerebrovascular accident and atherosclerosis & $437.0,437.1$ \\
\hline \multirow{5}{*}{$\begin{array}{l}\text { Peripheral arterial } \\
\text { disease }\end{array}$} & Carotid endarterectomy & $38.11,38.12$ \\
\hline & $\begin{array}{l}\text { Peripheral vascular bypass or peripheral artery } \\
\text { endarterectomy }\end{array}$ & $\begin{array}{l}38.26,39.28,39.24,39.20, \\
39.26,39.29\end{array}$ \\
\hline & Atherosclerosis of aorta & 440.0 \\
\hline & Atherosclerosis of peripheral arteries & 440.2 \\
\hline & Arterial embolism and thrombosis & 444 \\
\hline \multirow{3}{*}{$\begin{array}{l}\text { Aortic aneurysm or } \\
\text { dissection }\end{array}$} & Aortic aneurysm or dissection & 441 \\
\hline & Peripheral vascular disease, unspecified & 443.9 \\
\hline & Repair of aortic aneurysm & $38.44,38.45,39.54$ \\
\hline
\end{tabular}


GCA, as well as the long term risk of cardiovascular disease. ${ }^{39}$ Similarly, statin drug use may conceivably contribute to an overall reduction in cardiovascular risk among patients with GCA and increased $\mathrm{C}$ reactive protein. ${ }^{15}{ }^{40}$ These assumptions would be best tested in an observational study or a randomised clinical trial.

\section{Research ramifications}

Through multicentre collaboration, future researchers should also attempt to accurately classify and compare cardiovascular disease and related mortality among patients with and without GCA. Our post hoc subgroup analysis suggested that patients with GCA who are prescribed corticosteroids may experience a slightly lower rate of cardiovascular disease than patients not prescribed steroids. It would be worthwhile knowing whether GCA disease activity_reflected or according to ongoing steroid requirements-is correlated with cardiovascular disease. Examining sensitive and specific indicators of inflammation, alongside measured cardiolipin antibodies and certain markers of infection, may enhance our understanding of the pathophysiology linking GCA to cardiovascular disease. Finally, better documentation of the timing between the initial manifestation of GCA and that of cardiovascular disease, with a longer duration of follow up, may help clarify whether arterial occlusion is directly related to the arteritis, ${ }^{8}$ to secondary thrombosis, or to a more gradual progression to atherosclerosis.

\section{ACKNOWLEDGMENTS}

Thanks to Dr Donald A Redelmeier for his constructive comments in the design and presentation of this study.

\section{Authors' affiliations \\ J G Ray, Department of Medicine, St Michael's Hospital, University of Toronto, Toronto, Ontario, Canada \\ M M Mamdani ${ }^{*}$, Institute for Clinical Evaluative Sciences, Toronto, Ontario, Canada \\ W H Geerts, Department of Medicine, Sunnybrook and Women's College Health Sciences Centre, Toronto, Ontario, Canada}

*Also the Faculty of Pharmacy, University of Toronto, Toronto, Ontario, Canada

Potential conflict of interest: none.

\section{REFERENCES}

1 Mohan N, Kerr G. Spectrum of giant cell vasculitis. Curr Rheumatol Rep 2000;2:390-5

2 Freddo $T$, Price $M$, Kase $C$, et al. Myocardial infarction and coronary artery involvement in giant cell arteritis. Optom Vis Sci 1999;76:14-8.

3 Nesher G. Neurologic manifestations of giant cell arteritis. Clin Exp Rheumatol 2000; 18:S24-6.

4 Evans JM, O'Fallon WM, Hunder GG. Increased incidence of aortic aneurysm and dissection in giant cell (temporal) arteritis: a population-based study. Ann Intern Med 1995; 122:502-7.

5 Le Hello $C$, Levesque $H$, Jeanton $M$, et al. Lower limb giant cell arteritis and temporal arteritis: followup of 8 cases. J Rheumatol 2001;28:1407-12.

6 Wagner AD, Gerard HC, Fresemann T, et al. Detection of Chlamydia pneumoniae in giant cell vasculitis and correlation with the topographic arrangement of tissue-infiltrating dendritic cells. Arthritis Rheum 2000;43:1543-51.

7 Duhaut P, Berruyer $M$, Pinede L, et al. Anticardiolipin antibodies and giant cell arteritis: a prospective, multicenter case-control study. Groupe de Recherche sur l'Arterite a Cellules Geantes. Arthritis Rheum 1998:41:701-9.

8 Weyand CM, Goronzy JJ. Pathogenic mechanisms in giant cell arteritis. Cleve Clin J Med 2002;69(suppl 2):SII28-32.

9 Kalayoglu MV, Libby P, Byrne GI. Chlamydia pneumoniae as an emerging risk factor in cardiovascular disease. JAMA 2002;288:2724-31.

10 Lindholt JS, Ashton HA, Scott RA. Indicators of infection with Chlamydia pneumoniae are associated with expansion of abdominal aortic aneurysms. J Vasc Surg 2001;34:212-5.
11 Elkind MS, Lin IF, Grayston JT, et al. Chlamydia pneumoniae and the risk of first ischemic stroke: the Northern Manhattan stroke study. Stroke 2000;31:1521-5

12 Tuhrim S, Rand JH, Wu XX, et al. Elevated anticardiolipin antibody titer is a stroke risk factor in a multiethnic population independent of isotype or degree of positivity. Stroke 1999;30:1561-5.

13 Puisieux F, de Groote P, Masy E, et al. Association between anticardiolipin antibodies and mortality in patients with peripheral arterial disease. Am J Med 2000;109:635-41.

14 Van Der Meer IM, De Maat MP, Hak AE, et al. C-reactive protein predicts progression of atherosclerosis measured at various sites in the arterial tree: the Rotterdam study. Stroke 2002;33:2750-5

15 Ridker PM, Rifai N, Rose L, et al. Comparison of C-reactive protein and lowdensity lipoprotein cholesterol levels in the prediction of first cardiovascular events. N Engl J Med 2002;347:1557-65.

16 Machado EB, Gabriel SE, Beard CM, et al. A population-based case-control study of temporal arteritis: evidence for an association between temporal arteritis and degenerative vascular disease? Int J Epidemiol 1989;18:836-41.

17 Hachulla E, Boivin V, Pasturel-Michon U, et al. Prognostic factors and longterm evolution in a cohort of 133 patients with giant cell arteritis. Clin Exp Rheumatol 2001;19:171-6.

18 Singh G, Miller JD, Lee FH, et al. Prevalence of cardiovascular disease risk factors among US adults with self-reported osteoarthritis: data from the third national health and nutrition examination survey. Am J Manag Care 2002;8(15 suppl):S383-91.

19 Watson DJ, Rhodes T, Guess HA. All-cause mortality and vascular events among patients with rheumatoid arthritis, osteoarthritis, or no arthritis in the UK general practice research database. J Rheumatol 2003;30:1196-202.

20 Kobayashi S, Yano T, Matsumoto Y, et al. Clinical and epidemiologic analysis of giant cell (temporal) arteritis from a nationwide survey in 1998 in Japan: the first government-supported nationwide survey. Arthritis Rheum 2003;49:594-8.

21 lezzoni LI, Foley SM, Daley J, et al. Comorbidities, complications, and coding bias: does the number of diagnosis codes matter in predicting in-hospital mortality? JAMA 1992;267:2197-203.

22 Brenner H, Savitz DA, Gefeller O. The effects of joint misclassification of exposure and disease on epidemiologic measures of association. J Clin Epidemiol 1993;46:1195-202.

23 Austin PC, Daly PA, Tu JV. A multicenter study of the coding accuracy of hospital discharge administrative data for patients admitted to cardiac care units in Ontario. Am Heart J 2002;144:290-6.

24 Humphries KH, Rankin JM, Carere RG, et al. Co-morbidity data in outcomes research: are clinical data derived from administrative databases a reliable alternative to chart review? J Clin Epidemiol 2000;53:343-9.

25 Bisgard C, Sloth $\mathrm{H}$, Keiding $\mathrm{N}$, et al. Excess mortality in giant cell arteritis. $J$ Intern Med 1991;230:119-23.

26 Schaufelberger C, Bengtsson BA, Andersson R. Epidemiology and mortality in 220 patients with polymyalgia rheumatica. $\mathrm{Br} J$ Rheumatol 1995;34:261-4.

27 Gonzalez-Gay MA, Garcia-Porrua C, Vazquez-Caruncho M, et al. The spectrum of polymyalgia rheumatica in northwestern Spain: incidence and analysis of variables associated with relapse in a 10 year study. J Rheumatol 1999;26:1326-32.

28 Gran JT, Myklebust G, Wilsgaard T, et al. Survival in polymyalgia rheumatica and temporal arteritis: a study of 398 cases and matched population controls. Rheumatology 2001;40:1238-42.

29 Uddhammar A, Eriksson AL, Nystrom L, et al. Increased mortality due to cardiovascular disease in patients with giant cell arteritis in northern Sweden. J Rheumatol 2002;29:737-42.

30 Lie JT. Aortic and extracranial large vessel giant cell arteritis: a review of 72 cases with histopathologic documentation. Semin Arthritis Rheum 1995:24:422-31.

31 Gonzalez-Alegre $\mathbf{P}$, Ruiz-Lopez AD, Abarca-Costalago $M$, et al. Increment of the platelet count in temporal arteritis: response to therapy and ischemic complications. Eur Neurol 2001;45:43-5.

32 Liozon E, Venot J, Liozon F, et al. [Inflammation protein in Horton's disease: prospective study of 25 patients]. Ann Med Interne (Paris) 1990;141:319-24.

33 Folsom AR. Hemostatic risk factors for atherothrombotic disease: an epidemiologic view. Thromb Haemost 2001;86:366-73.

34 Duhaut $\mathbf{P}$, Pinede L, Demolombe-Rague S, et al. Giant cell arteritis and cardiovascular risk factors: a multicenter, prospective case-control study. Groupe de Recherche sur l'Arterite a Cellules Geantes. Arthritis Rheum 1998;41:1960-5

35 Emilie D, Liozon E, Crevon MC, et al. Production of interleukin 6 by granulomas of giant cell arteritis. Hum Immunol 1994;39:17-24.

36 Voskuyl AE, Zwinderman AH, Westedt ML, et al. The mortality of rheumatoid vasculitis compared with rheumatoid arthritis. Arthritis Rheum 1996;39:266-71.

37 Dessein PH, Stanwix AE, Joffe BI. Cardiovascular risk in rheumatoid arthritis versus osteoarthritis: acute phase response related decreased insulin sensitivity and high-density lipoprotein cholesterol as well as clustering of metabolic syndrome features in rheumatoid arthritis. Arthritis Res 2002;4:R5

38 Gabriel SE. The sensitivity and specificity of computerized databases for the diagnosis of rheumatoid arthritis. Arthritis Rheum 1994;37:821-3

39 Weyand CM, Kaiser M, Yang $\mathrm{H}$, et al. Therapeutic effects of acetylsalicylic acid in giant cell arteritis. Arthritis Rheum 2002;46:457-66.

40 Ansell BJ, Watson KE, Weiss RE, et al. hsCRP and HDL effects of statins trial (CHEST): rapid effect of statin therapy on C-reactive protein and high-density lipoprotein levels. A clinical investigation. Heart Dis 2003;5:2-7. 